\title{
Indiviidile suunatud käsitlusviis: lühike teoreetiline ja praktiline juhend ${ }^{*}$
}

\author{
Lars R. Bergman ${ }^{\mathrm{a} 1}$, Margit Wångby ${ }^{\mathrm{b}}$ \\ a Stockholm University \\ ${ }^{b}$ Lund University
}

\begin{abstract}
Annotatsioon
Lühike ülevaade indiviidile suunatud käsitlusviisist ${ }^{2}$ (person-oriented approach) koostati juhendmaterjaliks selle meetodi kasutamisest huvitatud uurijatele. Artiklis arutletakse meetodi teoreetiliste, metodoloogiliste ja praktiliste kaalutluste üle. Esiteks osutatakse mõningatele ajaloolistele juurtele. Sellele järgneb lühiülevaade holistlik-interaktsioonilisest uurimisparadigmast, mis moodustab indiviidikeskse käsitlusviisi üldise raami. Sellel käsitlusviisil on olemas nii teoreetiline kui ka metodoloogiline pool. Peale peamiste teoreetiliste tõekspidamiste tutvustatakse ka enam levinud indiviidikeskseid meetodeid. Indiviidile suunatud käsitlusviisi tuumaks on süsteemne vaade, mille kohaselt moodustavad süsteemi komponendid mustri, mida võiks pidada jagamatuks. Seda mustrit tuleks mõista ja uurida ühe tervikuna, mitte jagada tükkideks (variaabliteks/muutujateks), et neid tükke seejärel eraldiseisvate ühikutena uurida. Seega kasutatakse selliseid metodoloogilisi vahendeid, mis võimaldavad analüüsida tervikut (nt klasteranalüüs). Samuti esitatakse empiiriline näide koolihinnete arengumustrite uurimise kohta.
\end{abstract}

Võtmesõnad: indiviidile suunatud, individuaalne areng, pikilõikeline, klassid

\footnotetext{
Versioon: 11. november 2013.

1 Department of Psychology, Stockholm University, 10691 Stockholm, Sweden; lrb@psychology.su.se

2 Autorid teevad vahet terminitel person-oriented approach ja person-centered approach, mistõttu kasutati tõlkes mõnevõrra levinuma termini indiviidikeskne käsitlusviis asemel terminit indiviidile suunatud käsitlusviis. (Tõlk.)
} 


\section{Sissejuhatus}

Enne tänapäevase teadusliku psühholoogia teket oli psühholoogia hoopis teistsugune valdkond, kui see üleüldse eksisteeris. Näiteks seda, mida me praegusajal psühholoogiaks nimetame, peeti varem sageli osaks filosoofiast ning see lähtus palju vähem empiirilistest uurimustest ja kvantitatiivsete meetodite kasutamisest (Boring, 1950). „Vanasti” oli üsna levinud holistlik käsitlusviis, mis vaatles indiviidi tervikuna, näiteks nähti teda kuuluvat ühte mitmest tüübist, millest igaühele on iseloomulik komplekt domineerivaid tunnuseid. Selline mõtteviis esines juba vanadel kreeklastel. Näiteks väitsid Hippokratese koolkonna esindajad, eriti Galenos, et inimese nelja kehamahla - vere, musta sapi, kollase sapi ja lima - segu määrab ära, millist neljast temperamenditüübist inimene esindab: kas sangviinikut, koleerikut, melanhoolikut või flegmaatikut (Kagan, 1998). Tänapäevasele teaduslikule psühholoogiale eelnenud tüpoloogilist käsitlusviisi iseloomustas subjektiivsus ja empiiriliste uurimuste puudumine. See raskendas teaduslikku arengut ja tekitas ülekülluse sageli vildakatel alustel loodud tüpoloogiatest. Otse loomulikult on holistlik süsteemne käsitlusviis olnud sajandeid kasutuses teistes valdkondades, näiteks kasutas seda tänapäevase taksonoomiasüsteemi alusepanija Carl von Linné (1978).

19. sajandi alguses kerkis esile uut tüüpi, suuresti loodusteadustes välja töötatud tõhusatele uurimismeetoditele toetuv psühholoogia, mille esindajad rõhutasid empiiriliste uurimuste, eksperimentide, kvantifitseerimise ja tulemuste replikatsioonide tähtsust. Muutujast (variaablist) sai keskne mõisteline ja analüütiline ühik, mis võimaldas jagada tegelikkust erinevateks dimensioonideks ning uurida psühholoogilisi nähtusi struktureeritult ja detailselt. Seda soodustasid värskelt väljatöötatud võimsad statistilised meetodid. Selline muutujakeskne uurimisparadigma tõi endaga kaasa psühholoogiateadmiste plahvatusliku kasvu ning toetas tüpoloogilise käsitlusviisi kui millegi suuresti subjektiivse ja primitiivse seadmist kahtluse alla.

Viimaste aastakümnete jooksul on tänapäevasest füüsikast inspireerituna psühholoogias oma mõju suurendanud interaktsiooniline teoreetiline raamistik, milles nähakse indiviidi läbipõimunud komponentide dünaamilise süsteemina, mida on kõige parem mõista terviksüsteemi omaduste kaudu (nt Magnusson, 1988). Sellest perspektiivist vaadatuna ilmneb paljude uurimuste ülesehituses selge ebakõla uurijate kantud dünaamiliste protsesside käsitluse ja standardse muutujakeskse käsitlusviisi vahel (Bergman \& Vargha, 2013). Ent niisamuti on mingis ulatuses 
kooskõla moodsa terviksüsteemide vaate ja mitmete vanade tüpoloogiate taga oleva mõtlemise vahel. Interaktsioonilisest raamistikust on välja kujunenud indiviidile suunatud käsitlusviis, mille üheks teerajajaks saab pidada Jack Blocki (1971). Selle meetodi raames käsitletakse indiviidi funktsioneeriva tervikuna, mida on sageli kõige parem uurida, analüüsides infomustreid, mitte üksikuid tunnuseid, ja otsides nende mustrite hulgast tüüpilisemaid, mille kandjatest moodustub oluline alarühm kogu valimist. Mingil määral võib seda käsitlusviisi pidada tüpoloogiliseks, kuid erinevalt vanast tüpoloogilisest käsitlusviisist võimaldab see kvantifitseerimist, replikatsioone ning teooria testimise ja falsifitseerimise protseduure. Tüpoloogilise käsitlusega seob seda üksnes ühine lähtekoht: indiviidi peaks püüdma nii palju kui võimalik uurida korrastatud tervikuna (vt ka Bergman, Andershed, \& Andershed, 2009).

Artiklis esitatakse lühike ülevaade tänapäevasest indiviidile suunatud käsitlusviisist. Eesmärk on pakkuda lugejale suuniseid kõnealuse käsitlusviisi võimaluste ja piirangute nägemiseks seoses enda uurimisvaldkonnaga. Tehnilisi üksikasju ja sügavamaid arutelusid erinevatel teemadel pakuvad viited põhjalikumatele allikatele.

\section{Teoreetilised kaalutlused}

Tänapäevast indiviidile suunatud käsitlusviisi on kirjeldanud Bergman ja Magnusson (1997) ning Bergman, von Eye ja Magnusson (2006). Tasub silmas pidada, et sel käsitlusviisil on kaks tahku: 1) teoreetiline pool ja 2) metodoloogiline pool, mis sisaldab endas kõige loomulikumalt indiviidile suunatud uurimistöös kasutatavaid meetodeid (tavaliselt mustritele suunatud meetodid).

Holistlik-interaktsioonilises uurimisparadigmas nähakse indiviidi korrastatud tervikuna, mille elemendid on koostoimes, et saavutada komponentidevahelisi interaktsioone sisaldava dünaamilise protsessi töötav süsteem. Komponendid võivad olla erinevat tüüpi, näiteks käitumisviisid, bioloogilised tegurid, keskkonnategurid (Magnusson, 1988; Magnusson \& Törestad, 1993). See käsitlusviis on seotud dünaamiliste süsteemide käsitlusega, mis on olemas paljudes teistes teadusvaldkondades (vt nt Devaney, 1989; Kelso, 2000). Seda paradigmat saab rakendada suuna näitajana probleemi sõnastamisel, uurimisstrateegia ja metodoloogia valikul ja tulemuste tõlgendamisel peaaegu kõigis indiviidide uurimustes. Paradigma võib toimida ka lingua franca'na erinevate psühholoogia valdkondade uurijate ning psühholoogia ja lähedaste teaduste omavahelises 
interaktsioonis (Magnusson, 1996). Mitmed paradigma põhilised teoreetilised kontseptualiseeringud ei ole ainulaadsed, neid jagavad mitmed arenguteoreetikud, näiteks Bronfenbrenner ja Evans (2000) on lisatud uude „Arengu teadusesse” („Developmental Science”) (Cairns, Elder, \& Costello, 1996; Cicchetti, 2006).

Indiviidile suunatud käsitlusviisi teoreetilised kontseptualiseeringud lähtuvad holistlik-interaktsioonilisest uurimisparadigmast ning selle põhieeldusi on kirjeldanud Bergman ja Magnusson (1997). Järgnevalt on esitatud neli nendest eeldustest (modifitseeritud kujul).

1. Arenguliste protsesside kontseptuaalne mudel lähtub holistlik-interaktsioonilisest uurimisparadigmast. Seega on arenguprotsess osaliselt indiviidispetsiifiline.

2. Protsessi tasandid on omavahel hierarhiliselt seotud (st testi tegemisel liitub inimeses toimiv enda kogetud tegurite süsteem individuaalsete omaduste ja olukorra konteksti koosmõju süsteemiga). Arengu ja süsteemi erinevate tasandite toimimise aluseks on koherentsus ja struktuur.

3. Arengulised protsessid järgivad seaduspärasid, mis on seotud talitlevate faktorite mustrina korrastatud ja funktsioneerivate struktuuridega. Nendel seaduspäradel arvatakse olevat indiviiditi ühiseid jooni, kuid neid ei saa pidada identseteks.

4. Arengu käigus ilmnevad sageli vaadeldava süsteemi komponentide tüüpilised mustrid nii inimese sees kui ka inimeste vahel. Bergman ja Magnusson (1997) väljendavad seda nii: „Olgugi et teoreetiliselt on olemas lóputu erinevuste variatiivsus, mis puudutab protsessi omadusi ja detailselt käsitletud olukordi, võib üldisemal tasandil tihti eristada siiski väikest hulka sagedamini esinevaid mustreid (levinud tüüpe)." Autorid esitavad seda oletust toetavaid tõendeid ja põhjusi, miks peaks seda empiiriliste andmete peal testima. Oletatud tüüpilistel mustritel on sarnasusi dünaamiliste süsteemide uuringutes vaadeldud atraktoritega ${ }^{3}$.

3 Attractor - muster, milles süsteemi koostisosade pidevad vastastikmõjud stabiliseeruvad ja mille ümber teised sarnased mustrid koonduvad. (Tõlk.) 


\section{Metodoloogilised kaalutlused}

Indiviidile suunatud käsitlusviisi teoreetiline vaade on kaasatud ka empiiriliste uuringute uurimismeetodite valikusse. Järgnevalt on esitatud kaks põhisuunist.

1. Metodoloogia peaks võimaldama vähemalt mingil määral teha järeldusi üksikisiku kohta. Molenaar (2004) ning von Eye ja Bergman (2003) on osutanud, et tavapärased muutujale suunatud meetodid, mida rakendatakse indiviidide hulga empiirilistel andmetel, tavaliselt seda nõuet ei täida. Selle kohta võib tuua järgmise näite: stabiilsuse koefitsiendina arvutatakse eel- ja järeltestis sama tunnuse mõõdetud tulemuste vaheline Pearsoni korrelatsioon. Kui see korrelatsioon on arvestatavalt suur (nt 0,60), tõlgendatakse seda sageli nii: „Indiviid, kes alustab madalalt, kaldub ka madalal lõpetama, ja indiviid, kes on alguses kõrgel, kaldub ka lõpus kõrgel olema." Kuid olukorras, kus seletatud variatiivsus on $0,60^{2}=0,36$, ei ole see väide üldiselt indiviiditasandil kindlasti õige. On arvestatav hulk indiviide, keda iseloomustab teistsugune arengutee. Näiteks võivad nad algul olla üle keskmise ja lõpus keskmisest allpool.

2. Metodoloogia peaks võimaldama teha järeldusi funktsioneerimise individuaalsete mustrite kohta. Tavapäraselt saab seda saavutada vaid siis, kui huvi pakkuva süsteemi põhimustrit (tavaliselt muutuja väärtuste vektorit) koheldakse analüüsis jagamatu ühikuna. Toome näite: kujutlege andmestikku, mis koosneb ainult kolmest süsteemi kirjeldavast binaarsest tunnusest. Järgmiseks kujutlege, et kõigi nende kolme tunnuse paaride vahelised seosed on nullid. Nüüd sisaldab see andmestik $2 \times 2 \times 2=8$ võimalikku väärtuste mustrit ja need mustrid võivad esineda selliste sagedustega, et ilmnevad tugevalt olulised tüüpilised mustrid, kuigi kõik paaridevahelised seosed on nullid. Uurija, kes ignoreerib mustrite infot ja analüüsib ainult tunnuste paaride vahelisi seoseid, võib ekslikult järeldada, et andmetes ei leidu huvitavat struktuuri. Sellist näidet kutsutakse Meehli paradoksiks (Meehl, 1950) ja see illustreerib tõsiasja, et me ei saa automaatselt eeldada, et korrelatsiooni või variatiivsuse-kovariatiivsuse maatriksid sisaldavad kogu olulist teavet andmestikus peituvate seoste kohta. Ent näiteks strukturaalsete võrrandite mudeldamise standardsetes rakendustes see oletus siiski tehakse ja mudeli sobivust hinnatakse mudeli suutlikkuse kaudu taastada korrelatsiooni maatriks. Eriti just indiviidile suunatud vaatenurgast ei ole selline eeldus vettpidav, sest andmestikus võib olla tüüpilisi mustreid (sarnased kõrgema taseme interaktsioonidega), mis ei peegeldu tunnuste paaride vaheliste seoste korrelatsiooni maatriksis. 


\section{Mõned levinumad meetodid, mida kasutatakse indiviidile suunatud empiirilises uurimuses}

\section{Üksikisiku uurimine}

Üks indiviidile suunatud käsitlusviise on üksikisiku uurimine (nt Molenaar, 2004; Nesselroade \& Ford, 1985). Esmalt uuritakse üksikisikuid eraldi, tavaliselt suure hulga mõõtmiste tulemusel saadud andmete põhjal. Seejärel püütakse saadud tulemusi üldistada ka teistele üksikisikutele, kasutades alt-üles-meetodit. Ühelt poolt on selline käsitlusviis hästi indiviidikeskne, sest fookuses on üksikisikud ja neid uuritakse põhjalikult. Teiselt poolt ei ole see tavapäraselt siiski indiviidile suunatud, sest analüüsitakse muutujaid, mitte mustreid.

\section{Infomustritel põhinev eksploratiivne klassifitseerimise analüïs}

Eksploratiivses klassifitseerimise analüüsis kasutatakse sageli klasteranalüüsi eesmärgiga leida andmetest tavaliselt mittekattuvaid klastreid/ rühmi (tüüpilisi mustreid), kus ühe klastri liikmetel on sarnased muutujate väärtuste mustrid. Kui analüüsitakse läbilõikelisi andmeid, on see käsitlusviis indiviidikeskne selles tähenduses, et fookuses on muster ja mingil määral ka indiviid, kuid läbilõikelise meetodi korral eiratakse indiviidikeskse käsitlusviisi olulist protsessi aspekti. See aspekt on klasteranalüüsipõhistes meetodites mingil määral olemas, kui analüüsitakse pikiuuringu andmeid. Üks selliseid meetodeid on klastrite seostamine pärast jääkide eemaldamist (linking of clusters after removal of a residue, LICUR; Bergman, Magnusson, \& El-Khouri, 2000). LICURi rakendades tehakse kahel või enamal mõõtmishetkel mõõdetud tunnuste komplektidele eraldi klasteranalüüsid ja seostatakse nende tulemusena saadud klassifikatsioonid omavahel. Sel moel saab mustrite tasandil hinnata strukturaalset ja individuaalset stabiilsust ning muutumist. Teine meetod on I-seisundite kui objektide analüüs (I-states as objects analysis, ISOA; Bergman, Nurmi, \& von Eye, 2012). ISOA rakendamisel hinnatakse tunnuste komplekti lühiajalist arengut, leides tavaliselt klasteranalüüsi abil ajas muutumatu klassifitseerimissüsteemi. Seejärel hinnatakse indiviidi klastritesse kuulumiste järgnevusi muutumatus klassifitseerimissüsteemis erinevate mõõtmishetkede jadas.

\section{Kõigi võimalike väärtuste mustrite otsene uurimine}

Keeruliste statistiliste meetodite rakendamine mustrite analüüsimisel kipub tekitama olukorra, kus analüüsitavatest andmetest kaugenetakse märkimisväärselt: neid nähakse läbi kompleksse läätse. Seetõttu on vaja 
meetodit, mis aitab uurijal otsesemalt näha ja kergemini mõista andmestruktuure. See vajadus on viinud konfiguratsioonide sagedusanalüüsi väljatöötamiseni (configural frequency analysis, CFA; Lienert \& Krauth, 1975; von Eye \& Pena, 2004). CFA põhimõte seisneb selles, et esmalt liigitatakse kõik mustris sisalduvad tunnused mõnesse kategooriasse (tavaliselt kahte või kolme) ja seejärel loetletakse kõik võimalikud tunnuste kategooriate kombinatsioonid. Iga mustri juures hinnatakse selle esinemissagedust ning seda, kas tegemist on tüübiga ehk kas muster esineb oluliselt sagedamini, kui võiks baasmudeli alusel oletada, või antitüübiga ehk kas muster esineb oluliselt harvemini, kui võiks oodata. CFA on arenenud terveks meetodite perekonnaks, mida saab rakendada väga erinevat tüüpi andmete, näiteks pikilõikeliste andmete analüüsimisel.

\section{Mudelipõhine klassifikatsioonide analüüs}

Hinnatakse statistilist mudelit, mis sisaldab latentset kategoriaalset tunnust, mille abil seletatakse andmestikus avalduvaid seoseid. Lisaks hinnatakse valimi põhjal selle mudeli parameetreid. See tähendab, et võimalik on määrata usaldusvahemikke ja anda hinnang mudeli sobivusele. Sellise analüüsimeetodi variandid on kategoriaalsete andmete analüüsimiseks mõeldud latentsete klasside analüüs (latent class analysis; Lazarsfeld \& Henry, 1968) ja pidevaid tunnuseid sisaldavate andmestike analüüsiks mõeldud latentse profiili analüüs (latent profile analysis; Gibson, 1959; Muthén, 2002). Neid meetodeid on laiendatud nii, et nende abil saaks uurida ka arengut, näiteks latentse ülemineku analüüs (latent transition analysis; Collins \& Wugalter, 1992) võimaldab kategoriaalsete andmete pikilõikelist analüüsi. Kui kõik vajalikud eeldused on täidetud, võiks eelistada mudelipõhist meetodit, samas võib suutlikkus tagasi lükata viletsat mudelit olla mõõduka suurusega valimite korral väike. Arutluse eksploratiivse vs. mudelipõhise klassifitseerimise plussidest ja miinustest leiab lugeja Sterba ja Baueri (2010) materjalidest.

\section{Mittelineaarseid dünaamilisi süsteeme hindavad mudelid}

Mittelineaarsete dünaamiliste süsteemide uurimise mudelid (models for studying nonlinear dynamic systems, NOLIDS; Barton, 1994; Boker, 2002; Granic \& Hollenstein, 2006) on imporditud loodusteadustest ning nende eesmärk on leida protsessi arenemise matemaatiline mudel. Tavaliselt saavutatakse see diferentsiaalvõrrandite komplekti abil, millega mudeldatakse aja jooksul süsteemis aset leidvaid muutusi. Ühelt poolt on NOLIDS täiesti indiviidile suunatud käsitlusviis, sest fookuses on kogu süsteemi areng, kuid teisalt võib selliseid mudeleid olla psühholoogia 
kontekstis raske rakendada: rakendamiseks ideaalsed on rohkete mõõtmishetkedega kontrollitud eksperimendid. Kuigi sageli võib tegeliku mudeli ehitamine olla väga keeruline, pakub NOLIDSi mudel indiviidile suunatud käsitlusviisi kasutava uurija jaoks mitmeid vajalikke omadusi. Näiteks võivad mitmed NOLIDSi mõisted, mis on enamiku psühholoogide jaoks uudsed (nt atraktor, kaos, orjastamine), osutuda kasulikeks abivahenditeks teoreetilises arutluses.

Indiviidile suunatud meetodist põhjalikuma ülevaate saamiseks soovitatakse lugejal tutvuda Bergmani jt (2000), Bogati, von Eye ja Bergmani (avaldamisel), Sterba ja Baueri (2010) ning von Eye ja Bergmani (2003) tekstiga.

\section{Empiiriline näide: koolihinnete areng 10.-13. eluaastani}

Kooskõlas selle ajakirja teemaga pärineb ka näide hariduspsühholoogia valdkonnast. Et näidata indiviidile suunatud käsitlusviisi võimalikult lihtsast küljest, on valitud selline näide, kus ei ole vaja kasutada keerukat metodoloogiat ning kus analüüsitakse minimaalset muutujate hulka.

Andmed pärinevad Rootsi pikaajalisest individuaalse arengu ja kohanemise uurimisprogrammist (individual development and adaptation, IDA; Magnusson, 1988). Analüüsi on kaasatud umbes tuhande lapse hinded rootsi keeles ja matemaatikas kahel mõõtmishetkel: kui lapsed olid 10-aastased ja kui samad lapsed olid 13-aastased. Hinded on esitatud skaalal 1-5, kus 5 on kõrgeim hinne. 10- ja 13-aastaseid lapsi hindasid erinevad õpetajad.

Tausta avamiseks kasutatakse lihtsat muutujale suunatud analüüsi (vt tabel 1).

Tabel 1. Korrelatsiooni maatriks ning keskmised hinded 10- ja 13-aastaselt

\begin{tabular}{l|c|c|c|c|c}
\hline & $\begin{array}{c}\text { Rootsi keel, } \\
\mathbf{1 0}\end{array}$ & $\begin{array}{c}\text { Mate- } \\
\text { maatika, 10 }\end{array}$ & $\begin{array}{c}\text { Rootsi keel, } \\
\mathbf{1 3}\end{array}$ & $\begin{array}{c}\text { Mate- } \\
\text { maatika, 13 }\end{array}$ & $\begin{array}{c}\text { Keskmine/ } \\
\text { SD }\end{array}$ \\
\hline Rootsi keel, 10 & 1 & 0,66 & 0,75 & 0,59 & $3,1 / 1,0$ \\
\hline Matemaatika, 10 & & 1 & 0,61 & 0,72 & $3,2 / 1,0$ \\
\hline Rootsi keel, 13 & & & 1 & & $3,1 / 0,9$ \\
\hline Matemaatika, 13 & & & & 1 & $3,2 / 1,0$ \\
\hline
\end{tabular}

Märkus. „Rootsi keel, 10” on rootsi keele hinne 10 aasta vanuselt. Mitmene lineaarne regressioon näitas, et mõlemad 10 aasta vanuselt saadud hinded ennustasid hindeid rootsi keeles ja matemaatikas, kui õpilane on 13 aastat vana („Rootsi keel, 13 " ja „Matemaatika, 13"), $R^{2}$ oli vastavalt 0,58 ja 0,54. Mõlema aine hinded olid olulised ennustajad, kuid tugevaim ennustaja oli sõltuva muutujaga sama tunnus, mõõdetuna kolm aastat varem. 
Tabelist 1 ilmneb, et rootsi keele ja matemaatika hinnete vahelised korrelatsioonid on mõlema vanuse korral üsna suured, samuti on suured nende stabiilsuskoefitsiendid. Keskmised näitajad on mõlemas vanuses lastel lähedal hindele 3 ja tunnuste standardhälbed on sarnased. Hinded korreleeruvad väga tugevalt ka standardiseeritud saavutustestide tulemustega (üle 0,80, ei ole esitatud tabelis 1). Kahe õppeaine hinded 11-aastastel õpilastel ennustavad oluliselt mõlema õppeaine hindeid 13-aastaselt, seletades variatiivsusest natuke üle $50 \%$.

Tabelis 2 on esitatud $5 \times 5=25$ võimaliku hindemustri suhtelised sagedused mõlema vanuse korral (10 ja 13 aasta vanuselt). Näiteks on ootuspäraselt kõige levinum muster 33 ja seda nii 10 -aastastel $(21,2 \%)$ kui ka 13-aastastel lastel (21,4\%). Samuti selgub, et 10 - ja 13-aastastel esineb samasugune hindemuster sagedamini, kui võiks juhusliku tõenäosusega arvata. Kõige selgemalt väljendub see võrdse hindemustriga õpilastel. Näiteks on $46,4 \%$ õpilastest, kel esialgu oli hindemustriks 55, sama muster ka 13-aastaselt - seda on 16,3 korda rohkem, kui oleks võinud juhuslikult oodata.

Tabel 2. Õpilaste rootsi keele ja matemaatika hinnete mustrite suhteline sagedus 10- ja 13-aastastel lastel

\begin{tabular}{|c|c|c|c|}
\hline $\begin{array}{c}\text { Hindemuster } \\
\text { (võrdne muster } \\
\text { poolpaksus kirjas) }\end{array}$ & $\begin{array}{c}\text { Suhteline } \\
\text { sagedus } \\
\text { 10-aastaselt \% }\end{array}$ & $\begin{array}{c}\text { Suhteline } \\
\text { sagedus } \\
\text { 13-aastaselt \% }\end{array}$ & $\begin{array}{c}\text { Hindemustri } \\
\text { oluline* individuaalne } \\
\text { stabiilsus \% }\end{array}$ \\
\hline 11 & 1,1 & 1,2 & \\
\hline 12 & 2,8 & 2,1 & \\
\hline 13 & 0,7 & 0,2 & \\
\hline 14 & 0,0 & 0,0 & \\
\hline 15 & 0,0 & 0,0 & \\
\hline 21 & 1,6 & 2,7 & \\
\hline 22 & 9,3 & 11,5 & $39,8(\times 3,2)$ \\
\hline 23 & 9,0 & 6,9 & $28,7(\times 4,2)$ \\
\hline 24 & 1,2 & 1,1 & \\
\hline 25 & 0,1 & 0,0 & \\
\hline 31 & 0,4 & 0,7 & \\
\hline 32 & 6,8 & 8,0 & $30,5(\times 3,8)$ \\
\hline 33 & 21,2 & 21,4 & $39,4(\times 1,8)$ \\
\hline
\end{tabular}




\begin{tabular}{|c|c|c|c|}
\hline $\begin{array}{c}\text { Hindemuster } \\
\text { (võrdne muster } \\
\text { poolpaksus kirjas) }\end{array}$ & $\begin{array}{c}\text { Suhteline } \\
\text { sagedus } \\
\text { 10-aastaselt \% }\end{array}$ & $\begin{array}{c}\text { Suhteline } \\
\text { sagedus } \\
\text { 13-aastaselt \% }\end{array}$ & $\begin{array}{c}\text { Hindemustri } \\
\text { oluline* individuaalne } \\
\text { stabiilsus } \%\end{array}$ \\
\hline 34 & 9,1 & 8,1 & $24,1(\times 3,3)$ \\
\hline 35 & 0,5 & 1,2 & \\
\hline 41 & 0,1 & 0,0 & \\
\hline 42 & 1,1 & 0,9 & \\
\hline 43 & 7,2 & 7,0 & $27,7(\times 3,8)$ \\
\hline 44 & 15,6 & 13,6 & $40,4(\times 3,1)$ \\
\hline 45 & 4,0 & 6,9 & $45,9(\times 6,5)$ \\
\hline 51 & 0,0 & 0,0 & \\
\hline 52 & 0,0 & 0,0 & \\
\hline 53 & 0,9 & 0,6 & \\
\hline 54 & 3,6 & 2,7 & $34,4(\times 12,2)$ \\
\hline 55 & 3,2 & 3,2 & $46,4(\times 16,3)$ \\
\hline Kokku & 100,0 & 100,0 & \\
\hline
\end{tabular}

Märkus. * Bonferroni parandusega tõenäosus, mis põhineb hüpergeomeetrilisel jaotusel, mille nominaalne tõenäosus on fikseeritud väärtusele $0,05 / 25$. Olulise stabiilsusega mustrite korral on esitatud protsent kõigist õpilastest, kel oli 13-aastaselt sama muster kui 10 -aastaselt. Sulgudes on toodud vaadeldud väärtuse ja sõltumatu mudeli alusel oodatud väärtuse suhe.

Individuaalset hindemustri arengut saab üksikasjalikumalt analüüsida 10ja 13-aastaste laste hindemustrite risttabeli järgi. See on $25 \times 25$ risttabel ja kui seda hoolikalt analüüsida, pakub see rikkalikult materjali indiviidile suunatud küsimustele vastamiseks. Sellise detailse info esitamine ja tõlgendamine ei ole lühikese empiirilise näite korral otstarbekas. Seega on siin näitena esitatud vaid mõned lihtsad küsimused, millele leiab $25 \times 25$ risttabeli abil vastused.

1. On teada, et hinded on üsnagi stabiilsed tunnused, kuid kui stabiilsed on hindemustrid kolme aasta vältel? Lühivastus: hindemustrid on ülimalt stabiilsed, 33,0\% õpilastest on mõlemas vanuses identse mustriga ja ainult $21,1 \%$ õpilastest muutub muster rohkem kui minimaalselt (st rohkem kui üks samm vähemalt ühes kahest õppeainest).

2. Kui haruldane on hinnete ulatuslik paranemine/halvenemine? Lühivastus: ainult $1,8 \%$ õpilastest parandab oma hinnet rohkem kui ühe 
punkti võrra ning vaid 3,0\% õpilastest halveneb hinne rohkem kui ühe punkti võrra ühes õppeaines.

3. Kas on mingi võimalus, et õpilane, kel on esialgu halvad hinded nii rootsi keeles kui ka matemaatikas, saab kolm aastat hiljem häid hindeid? Lühivastus: mitte ükski laps, kel oli 10-aastasena nii rootsi keeles kui ka matemaatikas hinne 2 või halvem, ei saa kolm aastat hiljem mõlemas aines hindest 4 paremat hinnet.

Kokkuvõtteks, muutujale suunatud analüüsi tulemused, mis on esitatud tabelis 1, näitavad rootsi keeles ja matemaatikas küllaltki suurt hinnete stabiilsust, kuid just eelkirjeldatud lihtsa indiviidile suunatud analüüsi tulemused andmestiku üksikasjalikuma mustrite hindamise kohta viitavad palju tugevamale hinnete stabiilsusele. Kui sellised tulemused ilmnevad ka teistes valimites, võib olla piisavalt alust väita, et õpilasel on peaaegu olematu võimalus oma hindeid oluliselt parandada, kui just mõnda mõjusat sekkumist ei rakendata.

\section{Mõned tehnilised kommentaarid empiirilise näite juurde}

Näites on kasutatud lihtsat ennustavat CFAd ja analüüsi saab edasi arendada teiste selle traditsiooni kohaste meetodite abil. Siinsete analüüside tuuma moodustas 10 ja 13 aasta vanuses saadud hinnete kombinatsioonide $(25 \times 25)$ risttabeli üksikute lahtrite analüüs. Hindemustri stabiilsusele viitavaid lahtreid (sama muster mõlemas vanuses, 25 lahtrit) hinnati selle põhjal, kas andmestikus vaadeldud sagedus on oodatust oluliselt suurem (tüübid CFA kohaselt). (Mõnes väiksemas risttabelis oleks huvitav otsida ka olulisi muutuse mustreid, hinnates ka kõiki teisi 625-25 lahtri väärtusi, kuid siin seda ei tehtud.) Kuna viidi läbi 25 testi, kasutati ka Bonferroni parandust, mille tulemusena oli nõutav olulisuse nivoo väärtus tasemel $0,05 / 25=0,002$, et tulemust saaks pidada tõeliselt oluliseks $5 \%$ tasemel. Enamasti kasutatakse selliseks analüüsiks standardset statistikapaketti, näiteks hinnatakse standardiseeritud kohandatud jääke (standardized adjusted residuals) SPSSi tulemustes, mis järgivad ligikaudselt standardset normaaljaotust. Väga väikese oodatud sageduse korral ei ole normaaljaotusega sarnasus aga kõige õigem, äärmistes otstes on see lausa väär. Sel juhul tuleks eelistada täpset olulisuse testimist ja normaaljaotuse asemel kasutada hüpergeomeetrilist jaotust. Seda jaotust kasutati näiteandmetes. 


\section{Praktilised näpunäited indiviidile suunatud käsitlusviisil põhinevateks uuringuteks}

Lühiduse pärast käsitletakse vaid kahte põhilist olukorda indiviidile suunatud uurimisviisis: 1) uurija püüab leida indiviidide valimis tüüpilisi mustreid ja kasutab selleks komplekti ligikaudu pidevaid tunnuseid, mis koos moodustavad analüüsitava väärtuste profiili (1. juhtum), ning 2) uurija huvitub individuaalsetest sekkumise mõjudest (2. juhtum).

\section{1. juhtum}

1. Esimene tähtsaim ülesanne on määrata kindlaks huvialune süsteem ja selle komponendid. Iga komponendi jaoks tuleb leida vastav muutuja andmestikus. See esimene ülesanne vajab kõige rohkem teoreetilist tuge, uurija peab olema suuteline põhjendama tunnuste valikut, millest uuritav muster või profiil koosneb. Näiteks ei saa olemasolevaid tunnuseid lihtsalt profili lisada põhimõtte „mida rohkem, seda parem” järgi, sest muutus profiili moodustavas tunnuste komplektis tähendab tavaliselt ka uuritava süsteemi muutumist. Isegi üksiktunnuse lisamine muudab klassifikatsiooni struktuuri ja seega analüüsi tulemusi. See asjaolu kehtib isegi siis, kui lisatav tunnus on juba profiilis oleva tunnusega seotud mõiste alternatiivne mõõtmine. (Näiteks, kahe erineva agressiivsuse mõõtmise kaasamine profiili kahe tunnusena annab teiste klassifitseerivas analüüsis osalevate komponentidega võrreldes agressiivsuse komponendile kahekordse kaalu. Seetõttu on parem moodustada neist kahest kaalutud summa ja liita see profiili ühe tunnusena.)

2. Kui profiili mustri tunnused on välja valitud, tuleb leida sobilik klassifitseerimismeetod. Sobilikud alternatiivid on nii eksploratiivne meetod klasteranalüüsi näol kui ka mudelipõhine meetod, nt latentsete profilide analüüs. Sageli on kasulik rakendada mõlemat klassifitseerimismeetodit ja seejärel võrrelda tulemusi. Ühelt poolt võimaldab suurem osa mudelipõhiseid meetodeid teha rangemaid oletusi andmete omaduste kohta (nt tunnused on normaaljaotusega, lokaalne sõltumatus nii, nagu see on mudelis defineeritud, on tõeline lokaalne sõltumatus) ning need on keerukamad kui enamik eksploratiivseid meetodeid. Teiselt poolt võimaldavad mudelipõhiste meetodite tulemused koos usaldusvahemikega testida mudelit ning mudeldada ka n-ö healoomulised mõõtmisvead (enamiku eksploratiivsete meetodite tulemused võivad olla moonutatud isegi mõõdukate mõõtmisvigade korral). Kui kasutatakse klasteranalüüsi, tuleks teooria põhjal otsustada, milline on sobiv vahend individuaalsete profiilide vahelise erinevuse hindamiseks. 
Sageli sobib selleks eukleidilise kauguse ruudu meetod, sest see võtab arvesse kahe profiili vahelisi erinevusi nii vormi kui ka taseme poolest.

3. Artikli maht ei võimalda arutleda pikemalt tehniliselt keeruliste mudelipõhiste meetodite üle, mistõttu keskendume eksploratiivse meetodi kasutamisele. Siiski saab mitmeid esitatud mõtteid rakendada ka mudelipõhise juhtumi korral.

4. Eksploratiivsel klassifitseerimisel kasutatakse sageli klasteranalüüsi, olemas on valik erinevaid algoritme. Aglomeratiivne (liitev) hierarhiline klasteranalüüs võib olla hea valik, kui kasutada näiteks Wardi meetodit, mis maksimeerib klasterlahenduse seletatud variatiivsust, või keskmiste seoste meetodit (average linkage, UPGMA), mis minimeerib klastri liikmete vahelisi keskmisi kaugusi. Et saada ülevaade klasterdamise meetoditest indiviidile suunatud käsitlusviisi kontekstis, on soovitatav tutvuda Bergmani jt (2000) materjaliga. Aeg-ajalt rakendatakse pärast esmast hierarhilise meetodiga klassifitseerimist ka ümberpaigutamise (relocation) meetodit, et suurendada klastrite sisemist homogeensust. Sageli see mingil määral ka saavutatakse, kuid kannatada saab esialgse lahenduse hierarhilisus (hierarhilises lahenduses on k-klastriga lahendus samaväärne k-1 klastriga lahendusega, erinevus seisneb vaid selles, et kaks k-klastriga lahenduse klastrit liituvad omavahel, kuid pärast ümberpaigutamise protseduuri see enam nii ei ole).

5. Kuidas jõuda hea klasterlahenduseni ja seda hinnata? Esiteks tuleb selgeks teha, et klasteranalüüsi ülesanne on palju raskem kui enamiku muutujale suunatud meetodite oma. Kujutleme, et uurija on kogunud andmeid $n=200$ isikult $k=7$ tunnuse kohta. Standardse muutujakeskse meetodi korral tekitatakse esmalt andmestikust kokkuvõte variatiivsuse-kovariatiivsuse maatriksi näol, mis põhineb lineaarse mudeli kehtivuse eeldusel. See maatriks sisaldab 28 infoühikut, mida peetakse järgneva analüüsi jaoks piisavaks sisendiks (nt see võimaldab koostada strukturaalsete võrrandite mudeli, mida võib pidada ka mudeliks, mis seletab variatiivsuse-kovariatiivsuse maatriksit). Erinevalt eelnimetatud klasteranalüüsi variantidest võetakse andmed kõigepealt kokku erinevuste (dissimilarity) maatriksina, mis koosneb kõigi indiviidide paaride vahelistest erinevustest. Eelkirjeldatud juhtumi korral sisaldab selline maatriks 19900 infoühikut, mis on klasteranalüüsi sisendiks. Klasteranalüüsiga püütakse jagada indiviidid klastritesse nii, et klastrisisesed erinevused on võimalikult väikesed. Mõistagi saab eesmärgini jõuda erinevaid meetodeid kasutades, mistõttu võivad ka tulemused erineda (st isegi lihtsa ühedimensioonilise juhtumi korral võivad sellised kirjeldavad tunnused nagu aritmeetiline keskmine 
ja mediaan erineda). Põhjendatud algoritmide korral on klastrite struktuuride vahelised erinevused tavaliselt vaid mõõdukad, kuid siiski on mõistlik kasutada kahte meetodit ja seejärel saadud tulemusi võrrelda. Hea klasterlahenduse ja sobiliku klastrite arvu valikul kehtivad mitmed kriteeriumid (vt ülevaadet nt Bergman et al., 2000). Üldkehtivateks kriteeriumiteks on klastristruktuuri teoreetiline tähenduslikkus, klastrite sisemine homogeensus, klastristruktuuri taasesitamine teiste klassifitseerimismeetodite või valimitega ning klastritevaheliste teoreetiliselt ootuspäraste erinevuste ilmnemine hinnatava tunnuse osas.

6. Enamikul klassifitseerimismeetoditel, millega sorditakse subjekte klassidesse või klastritesse nende mitme tunnuse väärtustel põhineva profiili alusel, on kaks piirangut: 1) populatsioonist moodustunud valimiga kaasneb valmitevaheline variatiivsus tulemustes, kuid eriti just populatsioonides, mis ei ole kuigi kitsad, võivad väikese analüüsitava valimi korral jääda väikesed klastrid eristamata; 2) kui kasutatakse eksploratiivset meetodit, näiteks klasteranalüüsi, on oluline, et profiili moodustavad tunnused on mõõdetud usaldusväärselt, sest muidu võivad mõõtmisvigade tekitatud kõrvalekalded (outliers) tulemusi moonutada. Tegelikult võivad sellist mõju avaldada ka tõelised kõrvalekalded (nagu näiteks regressioonanalüüsi korral), mistõttu võib osutuda vajalikuks kõrvalekalded enne analüüsi andmestikust eemaldada (Bergman, 1988).

7. Mitmed eespool kirjeldatud kaalutlused kehtivad ka keerukamates olukordades, näiteks pikilõikeliste andmete analüüsi sisaldavates arenguuurimustes.

8. Leidub mitmeid statistilise andmetöötluse pakette, mida saab indiviidile suunatud analüüsis kasutada. Kõige täielikum klasteranalüüsi pakett on Clustan (2005), kuid põhilisemaid klasteranalüüse saab teha ka selliste standardsete pakettidega nagu SPSS. Mudelipõhiste klassifikatsioonide korral sobib nii läbi- kui ka pikilõikelisteks analüüsideks Mplus (2013) ning kategoriaalsete tunnuste jaoks on olemas latentsete klasside ja latentse ülemineku analüüsi programm (LTA, 2013). Seevastu statistikapaketid SLEIPNER (2002) ja ROPstat (2011) on loodud spetsiaalselt indiviidile suunatud analüüsiks. Neid kaht paketti on võimalik kasutada ka elementaarse CFA jaoks, kuid keerukamate CFA analüüside tegemiseks sobivad näiteks von Eye (1998) loodud programmid. 


\section{2. juhtum}

1. Kujutleme lihtsat standardset sekkumise mõju uuringut, mille valimi subjektid on juhuslikkuse alusel jaotatud kas sekkumist saavasse rühma või kontrollrühma. Kogutud on sõltuva tunnuse eel- ja järeltestimise tulemused (nt KKT ${ }^{4}$ teraapia mõju hindamiseks on mõõdetud foobiasümptomite esinemise määra). Oletame edasi, et ANOVA näitas olulist sekkumise mõju suurusega $d=0,7$ ja uuring oli korralikult üles ehitatud. Tõenäoliselt on seejärel näidatud keskmist põhjuslikkust: rühmatasandil hinnatuna said patsiendid teraapiast kasu. Sellega enamik uuringutest piirdubki. Kuid kuidas on lood individuaalse kausaalsusega? Seda tüüpi uuringu puhul ilmneb isegi andmete pinnapealsel vaatlemisel, et sugugi mitte kõik ei saanud teraapiast kasu. Millised inimesed need on? Üldplaanis saab individuaalset sekkumise mõju hinnata sellega, kui vaadelda erinevust indiviidi tegeliku järeltesti tulemuse ja eeltesti põhjal ennustatud järeltesti tulemuse vahel, kasutades selleks kontrollrühmal põhinevat regressioonvõrrandit. Ent sellise erinevuse määramatuse vahemik kasvab koos sõltuva tunnuse reliaabluse vähenemisega. On teada, et väikese reliaabluse korral on see määramatus ebamugavalt suur (vt sellekohast näidet nt Bergman, 2010). Meie näites, kui reliaabluse oletatav väärtus on 0,80 , tähendab see seda, et enamiku isikute puhul ei ole võimalik otsustada, kas see konkreetne inimene sai teraapiast kasu või mitte.

2. Ülalkirjeldatud näide iseloomustab üldist printsiipi: selleks, et teha järeldusi indiviiditasandil, peab mõõtmise täpsus olema suur - suurem kui tavaliselt enamikus psühholoogiakontekstides (Bergman \& Andersson, 2010).

3. Kuna mõõtmistel puudub sageli suur reliaablus ja kasutatakse tavapäraseid rühmapõhiseid muutujale suunatud meetodeid, on tekkinud olukord, kus leidub väga vähe uurimusi, mis pakuvad tänapäevases psühholoogias muutujate asemel teavet isikute kohta. Näiteks uuris Carlson (1971) suurt hulka artikleid isiksuse uurimusi avaldavates ajakirjades. Ta leidis teavet peaaegu ainult variaablite kohta (erinevate rühmade keskmised väärtused, korrelatsioonid jms), kuid mitte midagi üksikisikute kohta. Tema artikli pealkiri oli „Kus on isiksuse uuringutes indiviid?” („Where is the person in personality research?”).

$4 \quad$ KKT - kognitiiv-käitumisteraapia. (Tõlk.) 


\section{Arutelu}

Loodetavasti näitas see lühiülevaade indiviidile suunatud käsitlusviisist seda, et empiirilises uurimuses tuleks kõnealust meetodit nii selle teoreetilise raamistiku kui ka sellesse raamistikku sobituvate meetodite kasutamisel kindlasti arvesse võtta. Millised on selle võimalikud puudused? Puuduste üle on arutlenud Bergman ja Andersson (2010) ning selle sisu võib kokku võtta nelja punktiga.

1. Indiviidile suunatud käsitlusviis üldise teoreetilise raamistikuna ei ole eriti vastuoluline, sest tõenäoliselt peab enamik uurijaid selle põhilisi teoreetilisi kontseptualiseeringuid kehtivaks. Ent teooria on siiski üsna üldine ja selle tôlkimine empiiriliselt kontrollitavatesse hüpoteesidesse võib olla keeruline. Üks põhjusi on selles, et pea kõigis valdkondades on senine teadusliku teadmise kogum muutujakeskne, mitte indiviidile suunatud, mistõttu on see indiviidile suunatud teooria täpsustamisel piiratud kasutatavusega. Samuti on väga tähtis määrata kindlaks uuritav süsteem, sh valida süsteemi esindavate tunnuste adekvaatne komplekt. Kuna üksikuurimusse ei ole võimalik kaasata indiviidi keerukust tervikuna, piirdutakse indiviidile suunatud uurimise praktikas tavaliselt lihtsustatud väikese süsteemi ühetasandilise uurimisega. See ei ole küll piisav, kuid siiski parem kui kõigi süsteemi omaduste ignoreerimine, nagu seda enamasti tehakse muutujale suunatud uurimisviisi korral.

2. Indiviidile suunatud uurimuses sobib tavaliselt kasutada meetodeid, mille peamine analüüsiühik on tunnuste väärtuste muster. Mustritel põhinevad analüüsid kipuvad aga olema keerukamad kui muutujatel põhinevad analüüsid. Näiteks võib valimi jaotuse teooria loomine osutuda ülimalt vaevanõudvaks, kui sellesse kaasatud parameetrid on mitmest muutujast koosnevad keerulised üksused. Seega võivad metodoloogilised probleemid vähendada indiviidile suunatud käsitlusviisi kasulikkust.

3. Nagu eespool rõhutatud, nõuab indiviidile keskendumine sageli väga usaldusväärsete mõõtevahendite kasutamist. Praktikas võib see osutuda raskeks.

4. Nimetusele indiviidile suunatud ja muudele sarnastele nimetustele (nt indiviidikeskne, mustritele suunatud) on antud erinevaid tähendusi. Mõned uurijad lausa ignoreerivad indiviidile suunatud käsitlusviisi teoreetilisi osi ja määratlevad seda ainult meetodi kaudu (nt „see on klasteranalüüs”). See ei ole sellisel kujul küll tegelikult indiviidile suunatud käsitlusviisi puudus, kuid tekitab segadust. 
Indiviidile ja muutujale suunatud käsitlusviisi on aeg-ajalt võrreldud nende võime poolest ennustada olulist tulemust (Asendorpf, 2003; Bergman \& Trost, 2006). Tüüpiline olukord on järgmine: 1) muutujate komplekti käsitletakse mustrina ja sellele rakendatakse klasteranalüüsi, mille tulemusena esitatakse hulk andmestikus peituvate tüüpiliste mustrite kirjeldusi sisaldavaid klastreid; 2) mustris sisalduvaid muutujaid käsitletakse üksiktunnustena ja kõik need sisestatakse tulemuse ennustajana multi-regressioonanalüüsi. Lõpuks lisatakse ennustajatena ka klastrisse kuulumist näitavad alternatiivse kodeeringuga muutujad (nn dummy variables), et näha, kas need parandavad mudeli ennustusvõimet. Vahel annab see tulemusi, vahel mitte. Siinkohal on paslik esitada kaks kommentaari. Esiteks, mitme muutujaga andmestiku kirjeldamine klastrisse kuuluvuse kaudu tähendab ülilühikest kokkuvõtet (sisuks on tavaliselt ainult üks kategoriaalne tunnus 3-10 kategoriaalse väärtusega). Ent andmestiku kirjeldamine mitme piisavalt pideva tunnuse abil on palju vähem kokku surutud, tavaliselt tekib mitmeid tuhandeid väärtuste kombinatsioone. Selles valguses on üllatav, et klastrisse kuulumine on sageli vähemalt sama hea tulemuse ennustaja kui algsed tunnused. Occami habemenoa ${ }^{5}$ printsiibi kohaselt tuleks seda käsitlusviiside võrdlemisel ka arvesse võtta. Teiseks, seda, kui hästi mingit nähtust mõistetakse, ei saa hinnata ainult ennustusvõime põhjal, nagu on selle üle arutlenud Bergman ja Magnusson (1997). Näiteks on interaktsioonilises raamistikus formuleeritud teooriat sageli raske kontrollida, kui selleks kasutatakse empiirilistel andmetel põhinevat variaablikeskset uurimismeetodit, kuid kontrollimisel saab aluseks võtta indiviidile suunatud käsitlusviisi. Näitena sobib siinkohal tuua Lundhi, Saboonchi ja Wångby (2008) uurimuse positiivse ja negatiivse perfektsionismi kohta.

Paljud uurijad on viidanud üsna sagedasele mittevastavusele interaktsiooniliste ja dünaamiliste teoreetiliste formulatsioonide ning nende empiirilistel andmetel testimiseks kasutatavate statistiliste meetodite vahel (Bergman \& Magnusson, 1997; Bergman \& Vargha, 2013; Gottlieb, 1996; Richters, 1997). Näiteks kasutatakse analüüsides lineaarseid statistilisi mudeleid, mis ei sobitu uurija teoreetiliste kontseptualiseeringutega kokku, ning see viib olukorrani, kus tulemusi ei saa teoreetilise mudeli raames tõlgendada. Indiviidile suunatud käsitlusviis on sellistes olukordades sobilikem alternatiiv. Kui huvi keskmes on protsessi omadused, võib heaks alternatiiviks osutuda mittelineaarsete dünaamiliste süsteemide mudel (nonlinear dynamical systems model), kui selle jaoks on olemas

5 Occam's razor 'Occami habemenuga' - parismoonia- või ökonoomsusprintsiip. (Tõlk.) 
sobilikud andmed. Seda tüüpi mudeli parameetrid vastavad sageli interaktsioonilistele teoreetilistele kontseptualiseeringutele.

Oluline on mõista, et nii indiviidile kui ka muutujale suunatud käsitlusviisil, nagu nende üle siin artiklis on arutletud, on olemas teoreetiline ja metodoloogiline külg. Näiteks on mõningatel juhtudel võimalik indiviidile suunatud uuringus kasutada muutujakeskseid statistilisi meetodeid (nt uuritava süsteemi komponentide väärtuste spetsiifilist kombinatsiooni peetakse mingi kindla tulemuse seisukohalt kriitiliseks, selle kombinatsiooni jaoks tehakse alternatiivne kodeerimine ja lisatakse see koos teiste tunnustega ennustajana regressioonanalüüsi). Või vastupidi, muutujale suunatud teoreetilises raamistikus võib anda huvitavaid tulemusi interaktsioonide kontrollimine. Kui analüüsi on kaasatud palju muutujaid, võib suure hulga interaktsioonide kontrollimine muutuda keerukaks. Siis võib „paljutõotavate” interaktsioonide selgitamisel kasu olla sellisest meetodist nagu klasteranalüüs, kuid indiviidile suunatud raamistikus on kõige sobilikum siiski rakendada mustripõhist metodoloogiat. Mõnikord on abiks mõlema, nii indiviidile kui ka muutujale suunatud meetodite kasutamine, kuid nendel meetoditel saadud tulemused on sageli erinevad ning neid on keeruline võrrelda. See oleks umbes midagi sellist, nagu püüaks nägija, kuid kurt inimene võrrelda oma arusaama olukorrast pimeda, kuid kuulja inimese omaga. Indiviidile ja muutujale suunatud käsitluse võrdluse on esitanud Laursen ja Hoff (2006).

\section{Tänusõnad}

Uurimus sai teoks tänu võimalusele kasutada andmeid individuaalse arengu ja kohanemise (individual development and adaptation, IDA) pikaajalisest uurimisprojektist. IDA teadusjuhid on praegu Henrik ja AnnaKarin Andershed, enne neid olid Lars R. Bergman ja David Magnusson. David Magnusson vastutas siinses uurimuses kasutatud andmete kogumise kavandamise, elluviimise ja rahastamise eest. Andmete kogumist ja andmebaasi koostamist on grantidega toetanud Rootsi rahvuslik haridusamet, Rootsi uurimuste planeerimise ja koordineerimise komitee, Rootsi Panga kolmesajanda aastapäeva fond ja Rootsi sotsiaaluuringute nõukogu. 


\section{Kasutatud kirjandus}

Asendorpf, J. B. (2003). Head-to-head comparison of the predictive validity of personality types and dimensions. European Journal of Personality, 17(5), 327-346. http://dx.doi.org/10.1002/per.492

Barton, S. (1994). Chaos, self-organisation, and psychology. American Psychologist, 49(1), 5-14. http://dx.doi.org/10.1037/0003-066X.49.1.5

Bergman, L. R. (1988). You can't classify all of the people all of the time. Multivariate Behavioral Research, 23(4), 425-441.

http://dx.doi.org/10.1207/s15327906mbr2304_1

Bergman, L. R. (2010). The interpretation of single observational units' measurements. In M. Carlson, H. Nyquist, \& M. Villani (Eds.), Official statistics: Methodology and applications in honour of Daniel Thorburn (pp. 37-49). Stockholm: Stockholm University.

Bergman, L. R., Andershed, H., \& Andershed, A-K. (2009). Types and continua in developmental psychopathology: Problem behaviors in school and their relationship to later antisocial behavior. Development and Psychopathology, 21(3), 975992. http://dx.doi.org/10.1017/S0954579409000522

Bergman, L. R., \& Andersson, H. (2010). The person and the variable in developmental psychology. Journal of Psychology, 218(3), 155-165.

Bergman, L. R., \& Magnusson, D. (1997). A person-oriented approach in research on developmental psychopathology. Development and Psychopathology, 9(2), 291319. http://dx.doi.org/10.1017/S095457949700206X

Bergman, L. R., Magnusson, D., \& El-Khouri, B. M. (2000). Studying individual development in an interindividual context: A person-oriented approach. Mahwah, NJ: Erlbaum.

Bergman, L. R., Nurmi, J-E., \& von Eye, A. A. (2012). I-states-as-objects-analysis (ISOA): Extensions of an approach to studying short-term developmental processes by analyzing typical patterns. International Journal of Behavioral Development, 36(3), 237-246. http://dx.doi.org/10.1177/0165025412440947

Bergman, L. R., \& Trost, K. (2006). The person-oriented versus the variable-oriented approach: Are they complementary, opposites, or exploring different worlds? Merrill-Palmer Quarterly. Special Issue: Person-Centered and Variable-Centered Approaches to Longitudinal Data, 52(3), 601-632.

Bergman, L. R., \& Vargha, A. (2013). Matching method to problem: A developmental science perspective. European Journal of Developmental Psychology, 10(1), 9-28. http://dx.doi.org/10.1080/17405629.2012.732920

Bergman, L. R., von Eye, A., \& Magnusson, D. (2006). Person-oriented research strategies in developmental psychopathology. In D. Cicchetti \& D. J. Cohen (Eds.), Developmental psychopathology: Theory and method (2nd ed., Vol. 1, pp. 850-888). New York: John Wiley \& Sons.

Block, J. (1971). Lives through time. Berkeley, CA: Bancroft Books.

Bogat, A., von Eye, A., \& Bergman, L. R. (in press). Person-oriented approaches. In D. Cicchetti (Ed.), Developmental Psychopathology (3rd ed.). New York: John Wiley \& Sons. 
Boker, S. M. (2002). Consequences of continuity: The hunt for intrinsic properties within parameters of dynamics in psychological processes. Multivariate Behavioral Research, 37(3), 405-422. http://dx.doi.org/10.1207/S15327906MBR3703_5

Boring, E. G. (1950). A history of experimental psychology. New York: AppletonCentury-Crofts.

Bronfenbrenner, U., \& Evans, G. W. (2000). Developmental science in the 21st century: Emerging questions, theoretical models, research designs and empirical findings. Social Development, 9(1), 115-125. http://dx.doi.org/10.1111/1467-9507.00114

Cairns, R. B., Elder, G. H., Jr., \& Costello, E. J. (1996). Developmental Science. Cambridge: Cambridge University Press. http://dx.doi.org/10.1017/CBO9780511571114

Carlson, R. (1971). Where is the person in personality research? Psychological Bulletin, 75(3), 203-219. http://dx.doi.org/10.1037/h0030469

Cicchetti, D. (2006). Development and psychopathology. In D. Cicchetti (Ed.), Developmental psychopathology: Theory and method (2nd ed., Vol. 1, pp. 1-23). New York: John Wiley \& Sons.

Clustan (2005). A comprehensive statistical package for cluster analysis developed by David Wishart. Retrieved from www.clustan.com.

Collins, L. M., \& Wugalter, S. E. (1992). Latent class models for stage-sequential dynamic latent variables. Multivariate Behavioral Research, 27(1), 131-157. http://dx.doi.org/10.1207/s15327906mbr2701_8

Devaney, R. L. (1989). An introduction to chaotic dynamical systems. Redwood City, CA: Addison-Wesley.

Gibson, W. A. (1959). Three multivariate models: Factor analysis, latent structure analysis, and latent profile analysis. Psychometrika, 24(3), 229-248. http://dx.doi.org/10.1007/BF02289845

Gottlieb, G. (1996). A systems view of psychobiological development. In D. Magnusson (Ed.), The life-span development of individuals: Behavioral, neurobiological and psychosocial perspectives. A synthesis (pp. 76-103). Cambridge: Cambridge University Press.

Granic, I., \& Hollenstein, T. (2006). A survey of dynamic systems methods for developmental psychopathology. In D. Cicchetti \& D. J. Cohen (Eds.), Developmental psychopathology: Theory and method (2nd ed., Vol. 1, pp. 889-930). New York: John Wiley \& Sons.

Kagan, J. (1998). Galen's prophecy: Temperament in human nature. New York: Basic Books.

Kelso, J. A. (2000). Principles of dynamic pattern formation and change for a science of human behaviour. In L. R. Bergman, R. B. Cairns, L.-G. Nilsson, \& L. Nystedt (Eds.), Developmental science and the holistic approach (pp. 63-84). Mahwah, NJ: Erlbaum.

Lazarsfeld, P. F., \& Henry, N. W. (1968). Latent structure analysis. Boston: Houghton Miffin.

Laursen, B., \& Hoff, E. (2006). Person-centered and variable-centered approaches to longitudinal data. Merrill Palmer Quarterly, 52(3), 377-389.

http://dx.doi.org/10.1353/mpq.2006.0029 
Lienert, G. A., \& Krauth, J. (1975). Configural frequency analysis as a statistical tool for defining types. Educational and Psychological Measurement, 35(2), 231-238. http://dx.doi.org/10.1177/001316447503500201

Linné, v. C. (1978). Om Jämvikt i naturen. Carmina: Stockholm.

LTA (2013). PROC LCA \& PROC LTA (Version 1.3.0) [Software]. University Park: The Methodology Center, Penn State. Retrieved from http://methodology.psu.edu.

Lundh, L. G., Saboonchi, F., \& Wångby, M. (2008). The role of personal standards in clinically significant perfectionism. A person-oriented approach to the study of patterns of perfectionism. Cognitive Therapy and Research, 32(3), 333-350. http://dx.doi.org/10.1007/s10608-006-9109-7

Magnusson, D. (1988). Individual development from an interactional perspective: A longitudinal study. Hillsdale, NJ, England: Lawrence Erlbaum Associates.

Magnusson, D. (Ed.) (1996). The life-span development of individuals: Behavioral, neurobiological and psychosocial perspectives. Cambridge: Cambridge University Press.

Magnusson, D., \& Törestad, B. (1993). A holistic view of personality: A model revisited. Annual Review of Psychology, 44, 427-452. http://dx.doi.org/10.1146/annurev.ps.44.020193.002235

Meehl, P. E. (1950). Configural scoring. Journal of Consulting Psychology, 14(3), 165171. http://dx.doi.org/10.1037/h0058049

Molenaar, P. C. M. (2004). A manifesto on psychology as idiographic science: Bringing the person back into scientific psychology, this time forever. Measurement: Interdisciplinary Research and Perspectives, 2(4), 201-218. http://dx.doi.org/10.1207/s15366359mea0204_1

Mplus (2013). Mplus Version 7.11. Retrieved from www.statmodel.com.

Muthén, B. (2002). Beyond SEM: General latent variable modeling. Behaviormetrika, 29(1), 81-117. http://dx.doi.org/10.2333/bhmk.29.81

Nesselroade, J. R., \& Ford, D. H. (1985). P-technique comes of age: Multivariate, replicated, single-subject designs for research on older adults. Research on Aging, 7(1), 46-80. http://dx.doi.org/10.1177/0164027585007001003

Richters, J. E. (1997). The hubble hypothesis and the developmentalist's dilemma. Development and Psychopathology, 9(2), 193-229.

http://dx.doi.org/10.1017/S0954579497002022

ROPstat (2011). A statistical package for nonparametric and person-oriented analyses developed by András Vargha and Peter Bansagi. Retrieved from www.ropstat. com.

SLEIPNER (2002). A statistical package for person-oriented analysis developed by Lars R. Bergman and Bassam El-Khouri. Retrieved from www.psychology.su.se/ sleipner/.

Sterba, S. K., \& Bauer, D. J. (2010). Matching method with theory in person-oriented developmental psychopatology research. Development and Psychopathology, 22(2), 239-254. http://dx.doi.org/10.1017/S0954579410000015

Von Eye, A. (1998). Configural frequency analysis program for 32 bit operation systems. Methods of Psychological Research, 3(1), 1-3. 
Von Eye, A., \& Bergman, L. R. (2003). Research strategies in developmental psychopathology: Dimensional identity and the person-oriented approach. Development and Psychopathology, 15(3), 553-580.

http://dx.doi.org/10.1017/S0954579403000294

Von Eye, A., \& Pena, G. E. (2004). Configural frequency analysis: The search for extreme cells. Journal of Applied Statistics, 31(8), 981-997.

http://dx.doi.org/10.1080/0266476042000270545 